\title{
Regulation by Glycogen Synthase Kinase-3 $\beta$ of the Arborization Field and Maturation of Retinotectal Projection in Zebrafish
}

\author{
Hirofumi Tokuoka, Tomoyuki Yoshida, Naoto Matsuda, and Masayoshi Mishina \\ Department of Molecular Neurobiology and Pharmacology, Graduate School of Medicine, University of Tokyo, \\ and Solution-Oriented Research for Science and Technology, Japan Science and Technology Corporation, \\ Tokyo 113-0033, Japan
}

The retinotectal projection is one of the best systems to study the molecular basis of synapse formation in the CNS because of the well characterized topographic connections and activitydependent refinement. Here, we developed a presynaptic neuron-specific gene manipulation system in the zebrafish retinotectal projection in vivo using the nicotinic acetylcholine receptor $\beta 3$ (nAChR $\beta 3$ ) gene promoter. Enhanced green fluorescent protein (EGFP) expression signals in living transgenic zebrafish lines carrying the $n A C h R \beta 3$ gene promoter-directed EGFP expression vector visualized the development of entire retinal ganglion cell (RGC) axon projection to the tectum. Microinjection of the $n A C h R \beta 3$ gene promoter-driven doublecassette vectors directing the expression of both dominantnegative glycogen synthase kinase- $3 \beta$ (dnGSK-3 $\beta$ ) and EGFP enabled us to follow the development of individual RGCs and to

Neurons elaborate complex axonal arbors during brain development and establish their respective projection fields to form functional neural circuits. Regulation of the arborization is important for brain functioning. However, little is known about the molecular mechanisms determining the axonal projection field. Glycogen synthase kinase- $3 \beta$ (GSK-3 $\beta$ ) is a serine-threonine protein kinase that is implicated in various biological processes, including metabolic control, developmental patterning, cell survival, and tumorigenesis (Kim and Kimmel, 2000; Dominguez and Green, 2001; Grimes and Jope, 2001). The activity of GSK-3 $\beta$ is under complex regulation, including Wnt signaling (He et al., 1995) and growth factor signaling mediated by phosphatidylinositol-3 kinase (PI3K) and protein kinase B (PKB)/Akt (Cross et al., 1995). The brain expresses high levels of GSK-3 $\beta$ among tissues (Woodgett, 1990; Takahashi et al., 1994). In the developing rat brain, GSK-3 $\beta$ is abundant in growing axons of neurons, and GSK-3 $\beta$ levels are high at approximately postnatal day 20 (Takahashi et al., 1994; Leroy and Brion 1999), when synapse formation occurs actively (Stern et al., 2001). These observations raise a possibility that GSK- $3 \beta$ may be involved in

\footnotetext{
Received April 9, 2002; revised Aug. 29, 2002; accepted Sept. 9, 2002.

This work was supported in part by research grants from the Japan Science and Technology Corporation and the Ministry of Education, Culture, Sports, Science, and Technology of Japan. H.T. and T.Y. were recipients of the Fellowship for Young Scientists from the Japan Society for the Promotion of Science. We are grateful to K. Kinomoto for help in zebrafish breeding. We thank Dr. M. Kataoka for the plasmid VAMP2/pEGEP-N3.

Correspondence should be addressed to Masayoshi Mishina, Department of Molecular Neurobiology and Pharmacology, Graduate School of Medicine, University of Tokyo, Hongo 7-3-1, Bunkyo-ku, Tokyo 113-0033, Japan. E-mail: mishina@m.u-tokyo.ac.jp.

Copyright (C) 2002 Society for Neuroscience $0270-6474 / 02 / 2210324-09 \$ 15.00 / 0$
}

examine the effect of the molecule on the axonal arborization and maturation of the same neurons in living zebrafish. We found that the expression of the dominant-negative form of zebrafish GSK-3 $\beta$ suppressed the arborization field of RGC axon terminals in the tectum as estimated by the reduction of arbor branch length and arbor areas. Furthermore, the suppression of GSK-3 $\beta$ activity increased the size of vesicle-associated membrane protein 2-EGFP puncta in RGC axon terminals at the early stage of innervation to the tectum. These results suggest that GSK-3 $\beta$ regulates the arborization field and maturation of RGC axon terminals in vivo.

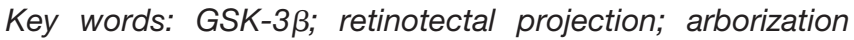
field; synapse maturation; zebrafish; nicotinic acetylcholine receptor $\beta 3$; vesicle-associated membrane protein 2 the signaling pathway for synaptogenesis. In support of this possibility, treatment of cultured dorsal root ganglion cells, cerebellar granule cells, and pontine neurons with lithium, an inhibitor of GSK-3 $\beta$, induced microtubule reorganization and the clustering of synapsin I (Lucas and Salinas, 1997; Hall et al., 2000). Wnt-7A mutation in mice delayed the formation and maturation of cerebellar mossy fiber-granule cell synapses (Hall et al., 2000). Although mutant mice lacking GSK-3 $\beta$ were embryonic lethal (Hoeflich et al., 2000), overexpression of GSK-3 $\beta$ in the mouse forebrain increased neural cell death (Lucas et al., 2001).

The retinotectal projection is one of the best systems to study the molecular basis of synapse formation in the CNS because of the well characterized topographic connections and activitydependent refinement (Cline and Constantine-Paton, 1990). The tectal neuropils near the head surface of the transparent zebrafish embryos are suitable for in vivo imaging of retinotectal projection by optic microscope. Blockade of action potentials by application of tetrodotoxin to zebrafish larvae between 2 and $4 \mathrm{~d}$ postfertilization (dpf) exerted little effect on the arbor fields of retinal ganglion cell (RGC) axons in the tectum (Stuermer et al., 1990), but treatment with the drug between 4 and $6 \mathrm{dpf}$ resulted in the enlargement of the projection field (Gnuegge et al., 2001). Here, we developed a presynaptic neuron-specific gene manipulation system in the zebrafish retinotectal projection in vivo using the nicotinic acetylcholine receptor $\beta 3(\mathrm{nAChR} \beta 3)$ gene promoter to investigate molecular mechanisms underlying synapse formation in the CNS. The expression of dominant-negative GSK-3 $\beta$ (dnGSK-3 $\beta$ ) in zebrafish RGC axons reduced axonal arbor size and increased the size of vesicle-associated membrane protein 2 (VAMP2)-enhanced green fluorescent protein (EGFP) fusion 
protein puncta. These results suggest that GSK-3 $\beta$ plays a role in controlling the arborization field and maturation of RGC axon terminals in the tectum.

\section{MATERIALS AND METHODS}

Animals. Zebrafish AB strain was used. Zebrafish embryos were raised at $28.5^{\circ} \mathrm{C}$ in embryo rearing solution (Easter and Nicola, 1996) containing the following (in mM): $17.1 \mathrm{NaCl}, 3.6 \mathrm{KCl}, 1.4 \mathrm{CaCl}_{2}$, and $0.40 \mathrm{MgSO}_{4}$. For microscopic observation, $0.2 \mathrm{~mm}$ phenylthiocarbamide was added to the embryo rearing solution at 8-12 $\mathrm{hr}$ postfertilization (hpf) to prevent melanocyte pigmentation (Westerfield, 1995). Adult fish were maintained on tap water dechlorinated with ion exchange resin with a controlled $12 \mathrm{hr}$ light/dark cycle at $28^{\circ} \mathrm{C}$.

Cloning of the zebrafish nAChR $\beta 3$ gene. The $0.42 \mathrm{~kb}$ DNA fragment of the zebrafish $n A C h R \beta 3$ gene was isolated by PCR with degenerate primers based on the coding sequence of the human, rat, chicken, and goldfish $n A C h R \beta 3$ genes (Cauley et al., 1989; Deneris et al., 1989; Hernandez et al., 1995; Elliott et al., 1996): 5'-AA(A/G)TT(C/T)GGI(A/T)(C/G)NTGGAC-3' and $5^{\prime}-\mathrm{A}(\mathrm{A} / \mathrm{G}) \mathrm{NGTNAC}(\mathrm{A} / \mathrm{G}) \mathrm{AA}(\mathrm{A} / \mathrm{T} / \mathrm{G}) \mathrm{ATCAT}(\mathrm{A} / \mathrm{T} / \mathrm{G}) \mathrm{AT}-$ (A/G)AA-3' (where I is inosine and $\mathrm{N}$ is four nucleotides). We obtained two types of zebrafish genomic DNA fragments with high nucleotide sequence identity with $n A C h R \beta 3$ genes of other species. One fragment showed 92.3 and $84.4 \%$ identity with two goldfish $n A C h R \beta 3$ homologs (Cauley et al., 1989), $n A C h R-n \alpha 2$ and $n A C h R-n \alpha 3$, respectively, and the other fragment had 85.8 and $95.8 \%$ identity, respectively. By screening a zebrafish BAC library (Incyte Genomics, St. Louis, MO) with one of the PCR fragments showing higher sequence identity with the goldfish $n A C h R$ $n \alpha 2$ gene as a probe, we isolated one genomic clone. The nucleotide sequences corresponding to exons 1 and 2 of the chicken $n A C h R \beta 3$ gene (Hernandez et al., 1995) were found on the $4.7 \mathrm{~kb}$ HindIII fragment of the genomic clone, and those corresponding to exons $4-6$ were followed by a polyadenylation signal on the $4.9 \mathrm{~kb}$ Bam $\mathrm{HI}$ fragment. We also isolated a cDNA clone encoding the entire zebrafish $n A C h R \beta 3$ coding region by reverse transcription (RT)-PCR of mRNAs prepared from embryos at 72 hpf using primers based on the sequence of the genomic fragments. The nucleotide and deduced amino acid sequences can be found in DNA Data Bank of Japan as accession number AB087185.

Construction of RGC-specific expression vectors. Zebrafish GSK-3 $\beta$ cDNA was cloned by PCR using a cDNA library prepared from embryos at $24 \mathrm{hpf}$ (Mori et al., 1994). Substitution mutations of the amino acid residues $85 \mathrm{~K}$ and $86 \mathrm{~K}$ to $85 \mathrm{M}$ and $86 \mathrm{I}$ were introduced into the cDNA by PCR to yield dnGSK-3 $\beta$ (He et al., 1995; Tsai et al., 2000). EGFP and VAMP2-EGFP coding sequences were obtained from pEGFP-N1 (Clontech, Palo Alto, CA) and VAMP2-pEGFP-N3 (kindly provided by Dr. M. Kataoka, Shinshu University, Nagano, Japan), respectively. The $0.7 \mathrm{~kb}$ EGFP, $1.3 \mathrm{~kb}$ zebrafish dnGSK- $3 \beta$, and $1.1 \mathrm{~kb}$ rat VAMP2EGFP fusion protein coding sequences were placed under the control of the $3.8 \mathrm{~kb} 5^{\prime}$ upstream sequence of the zebrafish $n A C h R \beta 3$ gene as an RGC-specific promoter and the $0.7 \mathrm{~kb} 3^{\prime}$ downstream sequence as a polyadenylation site to yield expression vectors promoter of $\mathrm{nAChR} \beta 3$ (PAR)-EGFP, PAR-dnGSK-3 $\beta$, and PAR-VAMP2-EGFP, respectively. The expression vectors were inserted between the HindIII and Bam HI sites of pBluescript II SK+ (Stratagene, La Jolla, CA). Expression vectors PAR-dnGSK-3 $\beta$ and PAR-EGFP were linked in a head-to-tail manner to yield PAR-dnGSK-3 $\beta$-EGFP, and PAR-dnGSK- $3 \beta$ and PARVAMP2-EGFP were linked to yield PAR-dnGSK-3 $\beta$-VAMP2-EGFP. Mouse Bassoon cDNA encoding the amino acid residues 1-627 (tom Dieck et al., 1998; Dresbach et al., 2001), enhanced yellow fluorescent protein (EYFP) coding sequence, and simian virus 40 polyadenylation signal sequence were fused and placed under the control of the $3.8 \mathrm{~kb} 5^{\prime}$ upstream sequence of the zebrafish $n A C h R \beta 3$ gene to yield PAR-Bassoon-EYFP. PAR-VAMP-enhanced cyan fluorescent protein (ECFP) was constructed by replacing the EGFP sequence of the PAR-VAMP2EGFP with the ECFP sequence from pECFP-N1 (Clontech).

Injection of expression vectors into zebrafish embryos and generation of transgenic lines. The expression vectors were linearized, purified by GeneCleanII (Bio101, Salana Beach, CA), and dissolved in $100 \mathrm{~mm} \mathrm{KCl}$ containing $0.05 \%$ phenol red. Approximately $0.2-0.5 \mathrm{nl}$ of the DNA solution at a concentration of $50-100 \mathrm{ng} / \mu \mathrm{l}$ was injected into the cytoplasm of one- to four-cell embryos. To generate stable transgenic lines, one-cell embryos were injected with PAR-EGFP vector. The injected embryos were maintained to sexual maturity and crossed with wild-type fish to examine the transmission of the transgene to the next generation. We obtained six transgenic lines stably expressing EGFP in RGCs, trigeminal ganglion cells, and Rohon-Beard neurons from 178 injected embryos.

Image collections. The EGFP signals in zebrafish embryos injected with expression vectors were examined under a fluorescence microscope at 72-76 hpf, and embryos showing signals in a few RGCs at the nasoventral retina were selected for further analyses. The embryos were anesthetized by $0.02 \%$ 3-aminobenzoic acid ethyl ester (tricaine; Sigma, St. Louis, MO) and embedded in 1\% agarose gel. Whole- body images were taken by a fluorescent stereoscopic microscope equipped with a DC300 digital camera (Leica, Wetzlar, Germany). Development of RGC axon arbors in the tectum was observed by $\mu$ Radiance confocal scanning system (BioRad, Hercules, CA) using Olympus Optical (Tokyo, Japan) $20 \times$ air lens [0.40 numerical aperture (NA)] and $60 \times$ oil lens (1.40 NA): zoom setting, 1.0 for whole axons, 3.0 for single axons; Z-step, $5 \mu \mathrm{m}$ for $20 \times$ lens, $2 \mu \mathrm{m}$ for $60 \times$ lens; image size, $512 \times 512$ pixels. For the observation of single axons, optical sections were collected through the depth of the whole arbor. Axons without a branch at $76 \mathrm{hpf}$ were excluded. Embryos were recovered from anesthesia during intervals between observations and monitored for blood flow and heartbeat. The EYFP and ECFP signals in zebrafish embryos coinjected with PAR-VAMP2-EGFP and PAR-Bassoon-EYFP were imaged at $96 \mathrm{hpf}$ with a Radiance 2100 confocal scanning system (Bio-Rad) using Nikon (Tokyo, Japan) $60 \times$ water lens (1.00 NA): zoom setting, 3.0; Z-step, $2 \mu \mathrm{m}$; image size, $512 \times 512$ pixels.

Data analysis. Quantitative measurements of RGC axon arbors were made on the computer screen using the NIH Image 1.62 program. Most axonal arbors were flat and extended in parallel to the tectal surface. In the rough estimation by three-dimensional reconstruction with $\mathrm{NIH}$ Image 1.62, the ratio of the vertical thickness of the axon arbors to the horizontal length was $0.28 \pm 0.03$ at $100 \mathrm{hpf}(n=16)$. The arbor planes at $100 \mathrm{hpf}$ were inclined by $51.8 \pm 3.3^{\circ}(n=16)$ from the focus plane of the microscope because of the curvature of the tectum. The autofluorescence of skin was removed from each optical section file, and twodimensional reconstruction of each axon was obtained (Zou and Cline, 1996; Schmidt et al., 2000; Gnuegge et al., 2001). All visible extensions were traced manually by density slice command and pen tool. Traced images were converted to binary mode and skeletonized. The first branch point and branch tips were connected, and arbor areas enclosed by the resulting convex polygon were measured. Total branch length within the arbor was calculated from the number of pixels covered by the arbors after skeletonization. The number of branch tips with branch length $>2$ $\mu \mathrm{m}$ was counted within the arbor. The numbers of branch tips added or deleted during arbor development were counted by comparing the images of axon terminals at 76, 84, and $100 \mathrm{hpf}$. The VAMP2-EGFP punctum was defined as an area in which the intensity of VAMP2-EGFP signals was four or more times stronger than that of nonvaricose and nonpunctate regions on the same axon. Contiguous puncta were separated from each other by placing a one-pixel- wide boundary (Silver and Stryker, 2000). Statistical significance was evaluated by repeatedmeasures ANOVA (split-plot type) (axonal arborization) and two-way ANOVA (VAMP2-EGFP puncta). When the interaction was significant, an unpaired $t$ test was used. One-way ANOVA was used for the statistical analysis of developmental changes of axonal arborization and VAMP2EGFP puncta.

\section{RESULTS}

\section{Visualization of developing zebrafish retinal ganglion cells in vivo}

The $\mathrm{nAChR} \beta 3$ is expressed predominantly in RGCs of chicken and goldfish (Cauley et al., 1989; Hernandez et al., 1995). We isolated the zebrafish $n A C h R \beta 3$ gene by PCR with degenerate primers based on the coding sequences of the human, rat, chicken, and goldfish $n A C h R \beta 3$ genes (Cauley et al., 1989; Deneris et al., 1989; Hernandez et al., 1995; Elliott et al., 1996). The deduced amino acid sequence of zebrafish nAChR $\beta 3$ shared 75.1, 73.9, 75.2, 93.3, and 79.8\% identity with human, rat, and chicken $\mathrm{nAChR} \beta 3$ and two goldfish counterparts, called nAChR-n $\alpha 2$ and nAChR-n $\alpha 3$, respectively (Cauley et al., 1989; Deneris et al., 1989; Hernandez et al., 1995; Elliott et al., 1996).

We constructed an EGFP expression vector using the $3.8 \mathrm{~kb} \mathrm{5}$ upstream sequence of the zebrafish $n A C h R \beta 3$ gene as an RGCspecific promoter and the $0.7 \mathrm{~kb} 3^{\prime}$ downstream sequence as a 
A


Figure 1. Visualization of RGC projection to the tectum in living zebrafish by $n A C h R \beta 3$ promoter-driven EGFP transgene. $A$, Structures of the zebrafish $n A C h R \beta 3$ gene (top) and nAChR $\beta 3$ promoter-driven EGFP expression vector (bottom). Filled boxes indicate putative exons of the zebrafish $n A C h R \beta 3$ gene. The EGFP expression vector consists of the 3.8 $\mathrm{kb} 5^{\prime}$ upstream sequence of the zebrafish $n A C h R \beta 3$ gene, the $0.7 \mathrm{~kb}$ EGFP coding sequence, and the $0.7 \mathrm{~kb} \mathrm{3}$ downstream sequence of the zebrafish $n A C h R \beta 3$ gene. B, BamHI; H, HindIII; N, NotI; S, SpeI; X, XbaI. $B$, Fluorescent signals in a transgenic zebrafish embryo at $72 \mathrm{hpf}$. Strong EGFP expression signals were found in RGCs in the retina (arrowhead), RGC axon terminals in the tectum (arrow), trigeminal ganglion cells ( $t g$ ), and Rohon-Beard neurons $(r b)$. $C$, Bright-field view of the transgenic zebrafish embryo at $72 \mathrm{hpf}$ shown in $B$. Scale bar, $0.5 \mathrm{~mm}$.

polyadenylation signal (Fig. 1A). The coding sequence of EGFP was inserted immediately downstream of the putative translational initiation codon of the zebrafish $n A C h R \beta 3$ gene in exon 1 . We injected the vector into fertilized zebrafish eggs and examined the expression of EGFP in embryos 2-5 d after injection under a fluorescence microscope. Most of the injected embryos showed EGFP signals in RGCs, suggesting that the $3.8 \mathrm{~kb} 5^{\prime}$ upstream sequence of the zebrafish $n A C h R \beta 3$ gene would be sufficient to direct the RGC-specific expression of exogenous genes. In addition to RGCs, EGFP signals were found in the trigeminal ganglion cells and Rohon-Beard neurons.

To further characterize the $n A C h R \beta 3$ gene promoter and to follow the development of the retinotectal projection in vivo, we generated transgenic zebrafish lines with the EGFP expression vector. Among 178 fish raised from eggs injected with the vector, six transgenic fish lines showed EGFP signals in the retina, RGC axon terminals in the tectum, trigeminal ganglion cells, and Rohon-Beard neurons (Fig. 1B,C). Inspection of transverse optical sections throughout the retina by confocal laser scanning microscopy revealed that EGFP signals were restricted to the RGC layer. In addition, weak EGFP signals were detectable in the lateral margin and deep caudal region of the tectum and sparsely in the hindbrain. In a few lines, EGFP signals were also found in heart or presumptive hypophysis, which might be reflecting the positional effects of the integration sites. However, no EGFP signals were detectable in the tectal neurons that extended axons or dendrites to tectal neuropil. Thus, the expression vector could selectively label the RGC projection in the retinotectal system.

\section{Development of the retinotectal projection in vivo}

We analyzed the development of RGCs in one of the transgenic lines with strong EGFP expression signals in vivo by confocal laser scanning microscopy (Fig. 2). EGFP signals in the line appeared in the ventronasal region of the retina at $30 \mathrm{hpf}$ (Fig. 2A,B), when RGCs began to differentiate (Malicki, 1999; Schmitt and Dowling, 1999). A significant number of EGFP-positive cells spread in the central region of the retina at $36 \mathrm{hpf}$, and RGC axons crossed the optic chiasm (Fig. 2C,D). At $48 \mathrm{hpf}$, the number of EGFPpositive cells increased further, and RGCs expanded in the inner retina to form the ganglion cell layer (Fig. $2 E, F$ ). The axon bundles of RGCs became thick and traversed lateral diencephalon to the rostrolateral tectum. The developmental time course of EGFP-labeled RGC axon projection into the tectum was in good agreement with previous observations by Stuermer (1988) and Burrill and Easter (1994). Several RGC axons extended in the rostrolateral tectum at $54 \mathrm{hpf}$ (Fig. 2G). At $60 \mathrm{hpf}$, the number of RGC axons in the tectum increased, and their axon terminals extended caudomedially (Fig. $2 H$ ). The shapes of the axons were rather straight and simple. The whole projection area of RGC axons expanded further and became round at $76 \mathrm{hpf}$ (Fig. $2 I$ ). The number of RGC axon bundles at the entrance of the tectal neuropil (rostrolateral margin of the tectum) increased, and the arborization of RGC axons became complex. At 84, 100, and 124 hpf, the whole projection area of RGC axons expanded gradually caudolaterally, whereas the number of RGC axon bundles remained rather constant (Fig. 2J-L). A meshwork of thick axon bundles developed prominently in the lateral tectum, whereas the axon bundles in the medial region were thinner (Fig. $2 L$ ). These observations suggested that the expansion and formation of the zebrafish retinotectal projection progressed rapidly in the initial $\sim 30 \mathrm{hr}$ and continued slowly thereafter.

\section{Dominant-negative GSK-3 $\beta$ reduced the arbor size of RGC axons}

To examine the role of GSK-3 $\beta$ in the development of the retinotectal projection, we designed a vector that directed the expression of both EGFP and dnGSK-3 $\beta$ under the control of the $n A C h R \beta 3$ promoter (PAR-dnGSK-3 $\beta$-EGFP) (Fig. $3 A$ ) by applying the double-cassette vector strategy (Yoshida et al., 2002). The EGFP expression vector PAR-EGFP served as a control. When injected into one- to four-cell stage embryos, the vectors labeled a few RGCs and visualized the morphology of individual axon arbors, including varicosities and filopodia in the tectum (Fig. $3 B, C)$. For the analyses of arborization, we chose RGC axon terminals innervating the caudomedial tectum (Fig. 3B), in which the arborization field was rather flat, and consecutively followed the development of RGC arbors at 76, 84, and $100 \mathrm{hpf}$ (Fig. 4). The projected images of the whole RGC axon terminals distal to the first branching point were reconstructed from their optical sections obtained by confocal laser scanning microscopy (Fig. 3D). We then measured three parameters to quantify the effect of dnGSK- $3 \beta$ on the RGC axon arborization: the arbor area enclosed by a simple convex polygon formed by connecting the first branching point and the branch tips, the total branch length within the arbor, and the number of branch tips with branch length longer than $2 \mu \mathrm{m}$ (Fig. $3 D$ ).

The branch length of RGC axon arbors in embryos injected with the control vector PAR-EGFP increased from 76 to $100 \mathrm{hpf}$ (one-way ANOVA; $F_{(2,84)}=11.49 ; p<0.0001$ ) (Fig. $5 A$ ). There was also a significant increase in the area of RGC arbors during these developmental stages (one-way ANOVA; $F_{(2,84)}=10.15$; 

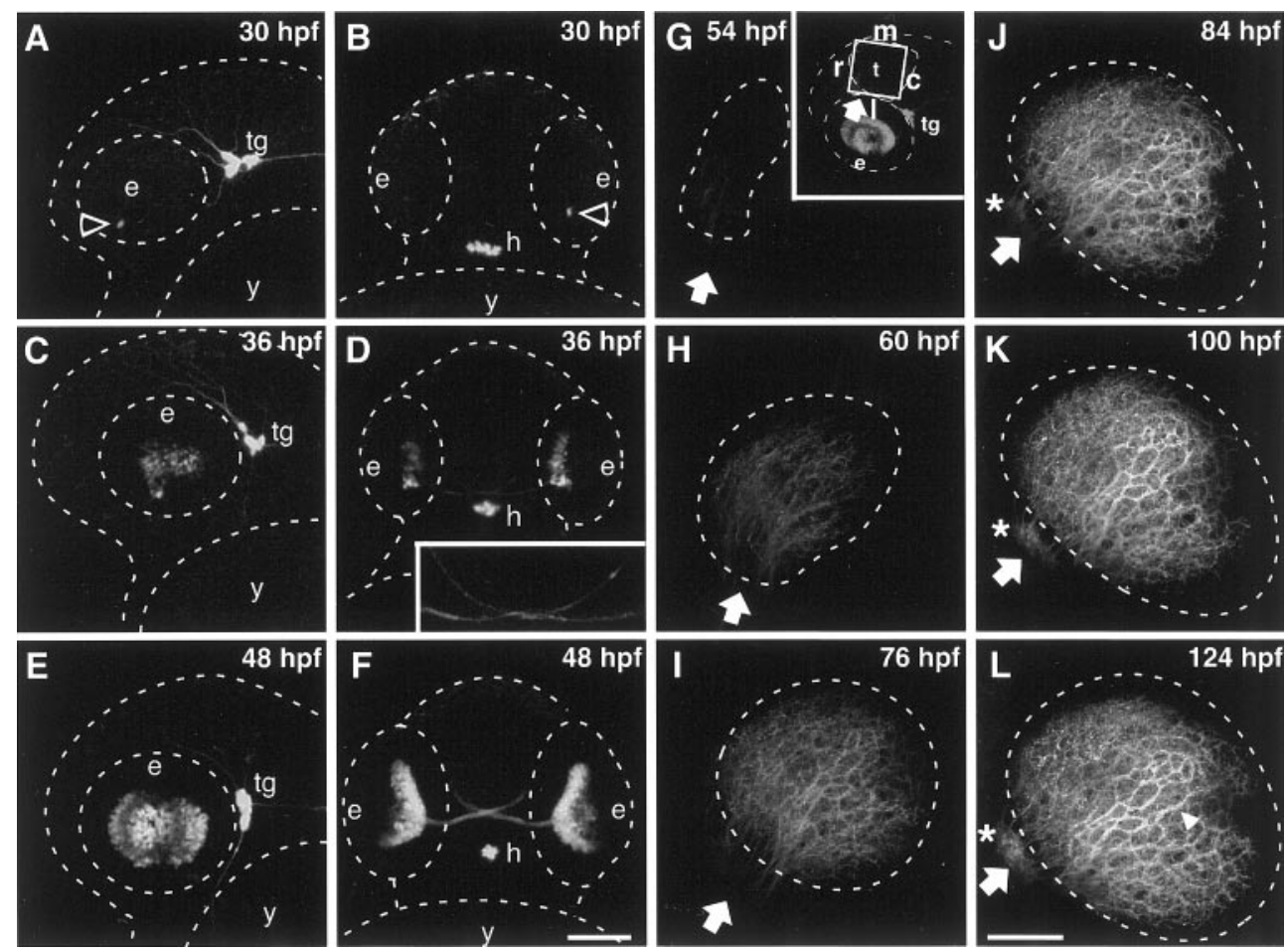

Figure 2. Development of the zebrafish retinotectal projection in vivo. EGFP expression signals in RGCs of transgenic zebrafish embryos were followed at various developmental stages by confocal laser scanning microscopy. $e$, Eye; $h$, hypophysis; $t g$, trigeminal ganglion cells; $y$, yolk; $t$, tectum. Scale bars: $A-F, 100 \mu \mathrm{m}$; $D$, inset, $30 \mu \mathrm{m} ; G-J, 50 \mu \mathrm{m}$. $A, B$, Lateral $(A)$ and frontal $(B)$ views of the head of an embryo at $30 \mathrm{hpf}$. EGFP signals were detected at the ventral retina (arrowheads). $C, D$, Lateral $(C)$ and frontal $(D)$ views of the head of an embryo at $36 \mathrm{hpf}$. $D$, Inset, RGC axons crossing optic chiasm. $E, F$, Lateral $(E)$ and frontal $(F)$ views of the head of an embryo at $48 \mathrm{hpf}$. $G-L$, Lateral views of the tectum of an embryo at $54(G), 60(H), 76(I), 84(J)$, $100(K)$, and $124(L)$ hpf. Dashed lines indicate the area of the tectal neuropil, and asterisks indicate the pretectal arborization field of RGC axons. Arrows point to the rostrolateral margin in which RGC axons entered the tectum. $G$, Inset, Lateral view of the head of the embryo at 54 hpf. $r$, Rostral; $l$, lateral; $c$, caudal; $m$, medial. Arrowhead in $L$ indicates the axonal bundle in the tectum. $p=0.0001$ ) (Fig. $5 C$ ). On the other hand, the branch tip number of RGC axons showed no significant changes during these periods (one-way ANOVA; $F_{(2,84)}=0.77 ; p=0.47$ ) (Fig. $5 E$ ).

RGCs in embryos injected with the vector PAR-dnGSK-3 $\beta$ EGFP innervated the tectum at $\sim 54 \mathrm{hpf}$ as control RGCs in embryos injected with the EGFP vector did. At $76 \mathrm{hpf}$, the ratio of embryos showing the arborization of EGFP-labeled RGC axons into the tectum was comparable between the embryos injected with PAR-EGFP (73 of 140 embryos) and PAR-dnGSK$3 \beta$-EGFP (75 of 163 embryos) ( $\chi^{2}$ test; $p=0.31$ ). Furthermore, there were no significant differences in the branch length, arbor areas, and branch tip number of RGC axons between embryos injected with PAR-dnGSK-3 $\beta$-EGFP and those injected with control PAR-EGFP at $76 \mathrm{hpf}(t$ test; $p=0.70,0.87$, and 0.58 , respectively) (Fig. $5 A, C, E$ ). Thus, the expression of $\operatorname{dnGSK}-3 \beta$ seemed to exert little effect on the timing of RGC axonal extension to the tectum. However, dnGSK- $3 \beta$ significantly affected the developmental changes of the branch length of RGC axon terminals (repeated-measures ANOVA; age $\times$ expression vector interaction; $\left.F_{(2,114)}=6.33 ; p=0.002\right)$. At $100 \mathrm{hpf}$, the branch length of RGC axon terminals in PAR-dnGSK-3 $\beta$-EGFP-injected embryos was significantly shorter than that in PAR-EGFP-injected control embryos ( $t$ test; $p=0.02$ ) (Fig. $5 A$ ). The increase in the branch length of RGC axon terminals from 76 to $100 \mathrm{hpf}$ in PAR-dnGSK-3 $\beta$-EGFP-injected embryos was also significantly smaller than that in control embryos ( $t$ test; $p=0.003$ ) (Fig. $5 B)$. Furthermore, dnGSK-3 $\beta$ significantly affected the developmental changes of the arbor area of RGC axon terminals (repeated- measures ANOVA; age $\times$ expression vector interaction; $\left.F_{(2,114)}=3.06 ; p=0.05\right)$. At $100 \mathrm{hpf}$, the arbor area of the RGC axon terminal in PAR-dnGSK-3 $\beta$-EGFP-injected embryos was significantly smaller than that in PAR-EGFP-injected control embryos ( $t$ test; $p=0.02$ ) (Fig. 5C). The increase in the arbor areas of RGC axon terminals from 76 to $100 \mathrm{hpf}$ in PAR-dnGSK$3 \beta$-EGFP-injected embryos was also significantly smaller than that in control embryos ( $t$ test; $p=0.01$ ) (Fig. $5 D)$. There was no significant difference in the number of RGC axon branch tips between the control and PAR-dnGSK-3 $\beta$-EGFP-injected embryos (repeated-measures ANOVA; age $\times$ expression vector interaction, $F_{(2,114)}=1.81 ; p=0.17$; expression vector effect, $F_{(1,57)}=$ $2.56, p=0.11$; age effect, $\left.F_{(2,114)}=0.42, p=0.66\right)$ (Fig. $\left.5 E\right)$. The increase in the number of RGC axon branch tips from 76 to $100 \mathrm{hpf}$ was not significantly different between the control and dnGSK-3 $\beta$ injected embryos ( $t$ test; $p=0.08$ ) (Fig. $5 F$ ).

We also counted the numbers of branch tips added or deleted during RGC arbor development (Fig. 6). There were no significant differences in the numbers of branch tip addition and deletion from 76 to $84 \mathrm{hpf}$ between the control and PAR-dnGSK-3 $\beta$ EGFP-injected embryos ( $t$ test; $p=0.46$ and 0.84 , respectively) (Fig. $6 A$ ). From 84 to $100 \mathrm{hpf}$, however, dnGSK-3 $\beta$ significantly decreased the number of added branch tips ( $t$ test; $p=0.02$ ) (Fig. $6 B)$, whereas the numbers of deleted branch tips were comparable between the control and PAR-dnGSK-3 $\beta$-EGFP-injected embryos ( $t$ test; $p=0.19$ ).

\section{Stimulatory effect of dominant-negative GSK-3 $\beta$ on the development of VAMP2-EGFP puncta in RGC axon terminals}

We then constructed a double-cassette vector that directed the expression of VAMP2-EGFP fusion protein and dnGSK-3 $\beta$ under the control of the $\mathrm{nAChR} \beta 3$ promoter to examine the development of RGC axon terminals (PAR-dnGSK-3 $\beta$-VAMP2EGFP) (Fig. 7A). The RGCs in embryos injected with the vector PAR-VAMP2-EGFP served as a control. Strong punctate signals of VAMP2-EGFP fluorescence were present primarily within the varicosities, whereas weak signals were distributed diff usely along entire axon shafts (Fig. 7B). The expression of dnGSK-3 $\beta$ appeared to increase the size of VAMP2-EGFP puncta at $76 \mathrm{hpf}$ (Fig. $7 D$ ). For quantitative measurements, we defined the VAMP2EGFP punctum as an area in which the fluorescent signal intensity 
A

\section{PAR-EGFP}

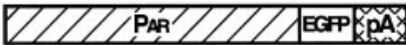

\section{PAR-dnGSK3 $\beta$-EGFP}
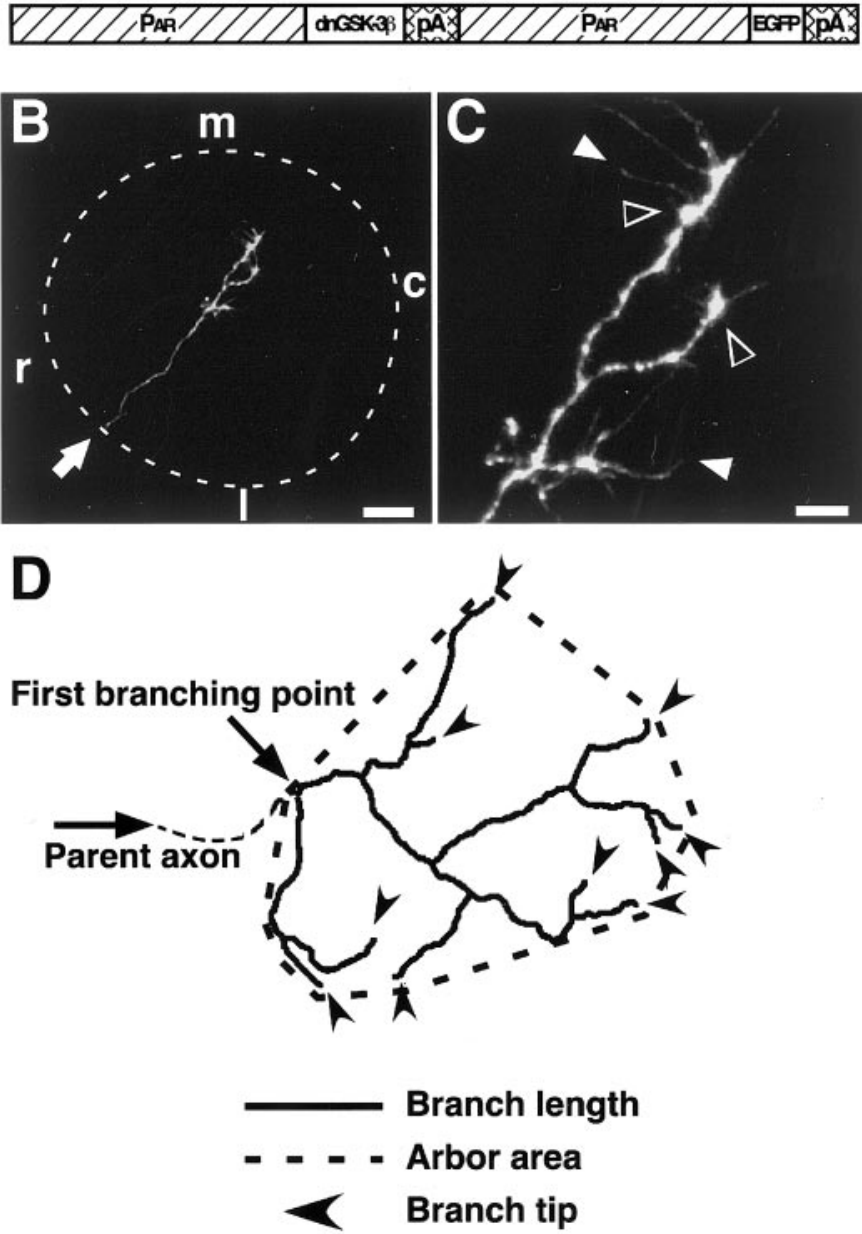

Figure 3. Analysis of single RGC axon arborization in the tectum. $A$, Structures of the $n A C h R \beta 3$ promoter-driven EGFP expression vector (top) and double-cassette expression vector of dnGSK-3 $\beta$ and EGFP (bottom). pA, Polyadenylation signal. $B$, Axon terminal arborization of a single RGC in the caudomedial tectum of a PAR-EGFP-injected embryo at 76 hpf. Arrow indicates the direction of axonal extension. Dashed line indicates the area of the tectal neuropil. $r$, Rostral; $l$, lateral; $c$, caudal; $m$, medial. Scale bar, $20 \mu \mathrm{m}$. $C$, Magnification of the RGC axon terminal in $B$. Varicosities (open arrowheads) and filopodia (filled arrowheads) were visible. Scale bar, $5 \mu \mathrm{m}$. $D$, Quantification of arbor morphology. Dashed line shows the arbor area defined by convex polygon made by connecting the first branch point with the tips of branches. The branch length is obtained by measuring the length of all branches within the arbor area. The number of branch tips with branch length $>2 \mu \mathrm{m}$ is counted in the arbor area.

was four or more times stronger than the averaged intensity of nonvaricose and nonpunctate regions on the same axon (Fig. 7C,E). In control embryos at $100 \mathrm{hpf}, 68 \pm 3 \%$ (mean \pm SEM) of VAMP2EGFP puncta $(n=21)$ were found in varicosities that were defined morphologically as axonal swelling exceeding the typical variation in diameter of the adjacent axonal shafts by $>50 \%$ (Shepherd and Harris, 1998), and $79 \pm 5 \%$ of varicosities contained VAMP2EGFP puncta.
$76 \mathrm{hpf}$
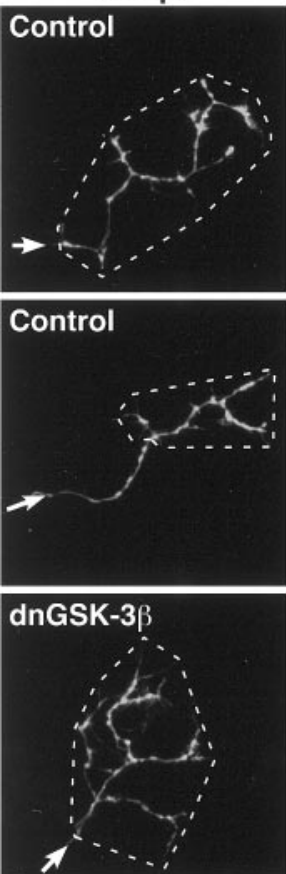

dnGSK-3 $\beta$

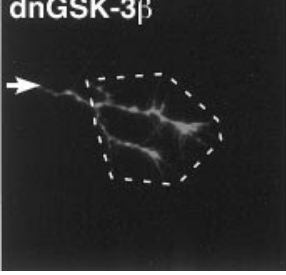

$84 \mathrm{hpf}$


$100 \mathrm{hpf}$


Figure 4. Representative images of RGC axon terminals of the PAREGFP-injected control and PAR-dnGSK-3 $\beta$-EGFP-injected embryos at 76, 84, and $100 \mathrm{hpf}$. Axon terminals of respective RGCs were observed consecutively by confocal laser scanning microscopy. Dashed lines show the arbor area. Arrows indicate the parent axon of each arbor. Scale bar, $10 \mu \mathrm{m}$.

In control embryos injected with PAR-VAMP2-EGFP, both the size and number of VAMP2-EGFP puncta in RGC axon terminals increased significantly during development from 76 to 100 hpf (one-way ANOVA; puncta size, $F_{(2,795)}=7.0, p=0.001$; puncta number, $F_{(2,54)}=22.5, p<0.0001$ ) (Fig. $\left.7 F, G\right)$. The expression of dnGSK-3 $\beta$ significantly affected the developmental changes of the VAMP2-EGFP puncta size (two-way ANOVA; age $\times$ expression vector interaction; $\left.F_{(2,1473)}=3.68 ; p=0.03\right)$. The VAMP2-EGFP puncta in RGC axon terminals of embryos injected with PAR-dnGSK-3 $\beta$-VAMP2-EGFP were significantly larger than those of control embryos injected with PAR-VAMP2EGFP at 76 and $84 \mathrm{hpf}(t$ test; $p=0.02$ ) (Fig. $7 F)$. The sizes of VAMP2-EGFP puncta in RGC axon terminals were comparable among PAR-dnGSK-3 $\beta$-VAMP2-EGFP-injected embryos at 76, 84 , and $100 \mathrm{hpf}$ (one-way ANOVA; $F_{(2,678)}=0.16 ; p=0.85$ ). There was no significant difference in the number of VAMP2EGFP puncta in RGC axon terminals between PAR-dnGSK-3 $\beta$ VAMP2-EGFP-injected and control PAR-VAMP2-EGFPinjected embryos (two-way ANOVA; age $\times$ expression vector interaction, $F_{(2,103)}=2.5, p=0.09$; expression vector effect, $F_{(1,103)}=0.17, p=0.68$ ) (Fig. $7 G$ ). The number of VAMP2EGFP puncta in RGC axon terminals increased from 76 to 100 

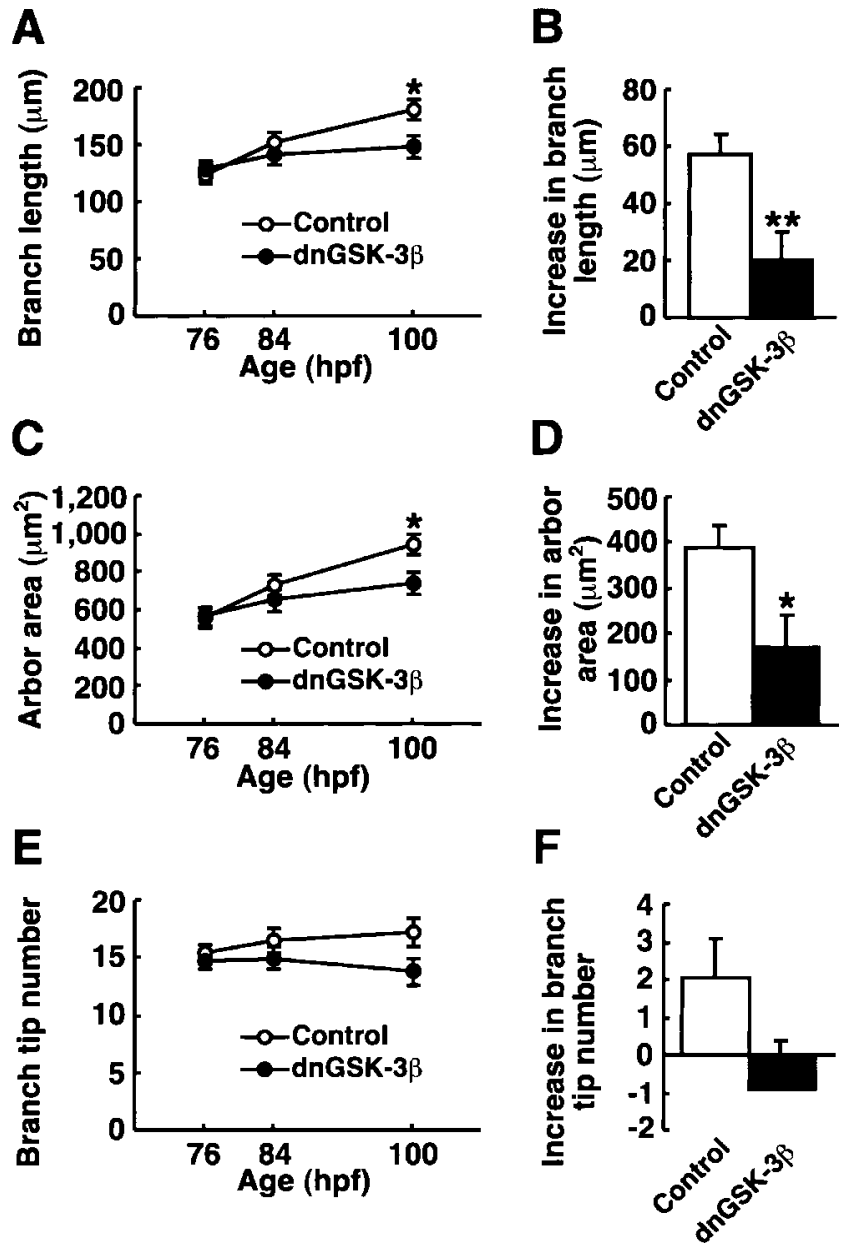

Figure 5. Effect of the dominant-negative form of GSK-3 $\beta$ on the development of RGC axon terminals in the tectum. The branch length, arbor area, and number of branch tips of PAR-EGFP-injected control (open symbols; $n=29$ ) and PAR-dnGSK-3 $\beta$-EGFP-injected (filled symbols; $n=30$ ) embryos were measured consecutively at 76, 84, and $100 \mathrm{hpf}$. ${ }^{*} p<0.05 ;{ }^{*} p<0.01 ; t$ test. $A$, Branch length. $B$, Increase of branch length from 76 to $100 \mathrm{hpf}$. $C$, Arbor area. $D$, Increase of arbor area. $E$, Branch tip number. $F$, Increase of branch tip number.

hpf in PAR-dnGSK-3 $\beta$-VAMP2-EGFP-injected embryos (oneway ANOVA; $\left.F_{(2,49)}=5.8 ; p=0.005\right)$.

To verify further that the VAMP2 puncta represented the synaptic sites, we examined their colocalization with Bassoon because Bassoon is localized selectively at the active zone of presynaptic nerve terminals (tom Dieck et al., 1998; Dresbach et al., 2001). Injection of zebrafish embryos with PAR-VAMP2ECFP and PAR-Bassoon-EYFP revealed that signals of VAMP2ECFP and Bassoon-EYFP fluorescence were primarily punctate in the RGC axon terminals and were well merged (Fig. 8).

\section{DISCUSSION}

The retinotectal projection is one of the best systems to study the molecular basis of synapse formation in the CNS because of the well characterized topographic connections and activitydependent refinement (Stuermer, 1988; Cline and ConstantinePaton, 1990; Zou and Cline, 1999; Alsina et al., 2001; Gnuegge et al., 2001). Here, we developed a presynaptic neuron-specific gene manipulation system in the zebrafish retinotectal projection in vivo using the $n A C h R \beta 3$ gene promoter. Microinjection of the
A

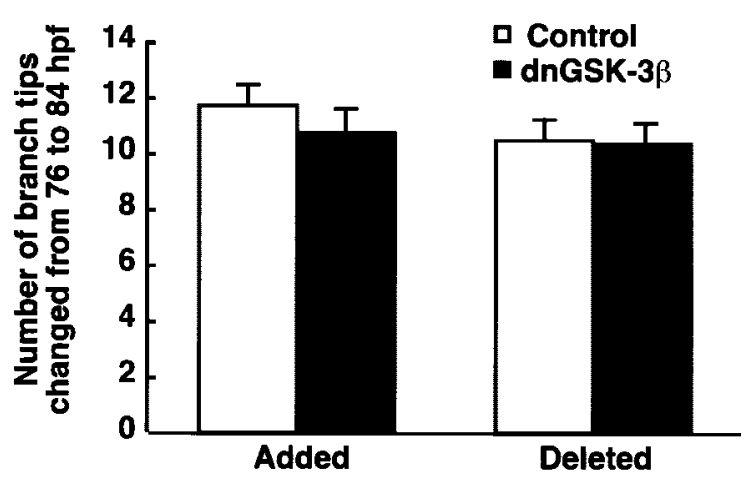

B

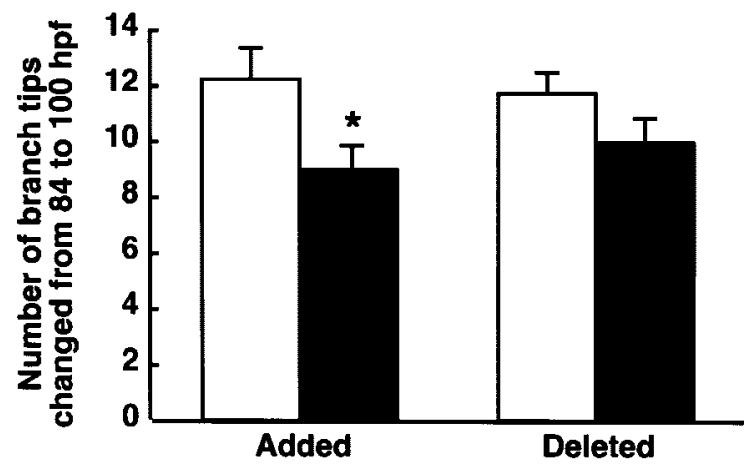

Figure 6. Effect of the dominant-negative form of GSK-3 $\beta$ on the dynamics of RGC axon terminal branches. $A, B$, The numbers of branch tips added and deleted from 76 to $84 \mathrm{hpf}(A)$ and from 84 to $100 \mathrm{hpf}(B)$ in PAR-EGFP-injected control $(n=29)$ and PAR-dnGSK-3 $\beta$-EGFPinjected $(n=30)$ embryos. ${ }^{*} p<0.05 ; t$ test.

$n A C h R \beta 3$ gene promoter-driven double-cassette vectors directing the expression of both dnGSK-3 $\beta$ and EGFP enabled us to follow the development of individual RGCs and to examine the effect of the molecule on the axonal arborization and maturation of the same neurons in living zebrafish.

We isolated two types of zebrafish genomic DNA fragments by PCR with degenerate primers based on the coding sequence of the human, rat, chicken, and goldfish $n A C h R \beta 3$ genes (Cauley et al., 1989; Deneris et al., 1989; Hernandez et al., 1995; Elliott et al., 1996). The amino acid sequence encoded by one fragment showed 97.8 and $89.9 \%$ identity with two goldfish $\mathrm{nAChR} \beta 3$ homologs (corresponding to the amino acid residues 178-304) (Cauley et al., 1989); the other fragment had 90.6 and $98.6 \%$ identity, respectively. Thus, the zebrafish genome, like the goldfish genome, may contain two $n A C h R \beta 3$ homologs. Comparison of the nucleotide sequences suggested that the zebrafish $n A C h R \beta 3$ gene that we isolated was the zebrafish counterpart of the goldfish $n A C h R-n \alpha 2$ gene. In the retinotectal projection, the goldfish $n A C h R-n \alpha 2$ gene was expressed selectively in presynaptic RGCs, whereas the goldfish $n A C h R-n \alpha 3$ gene was expressed in both the presynaptic RGCs and the postsynaptic tectal neurons (Cauley et al., 1990). Consistently, the $3.8 \mathrm{~kb} 5^{\prime}$ upstream sequence of the zebrafish $n A C h R \beta 3$ gene directed the RGCspecific expression in the retinotectal projection in vivo.

We revealed the development of entire RGC axon projections to the tectum in living transgenic zebrafish lines carrying the $n A C h R \beta 3$ gene promoter-directed EGFP expression vector. The 
A
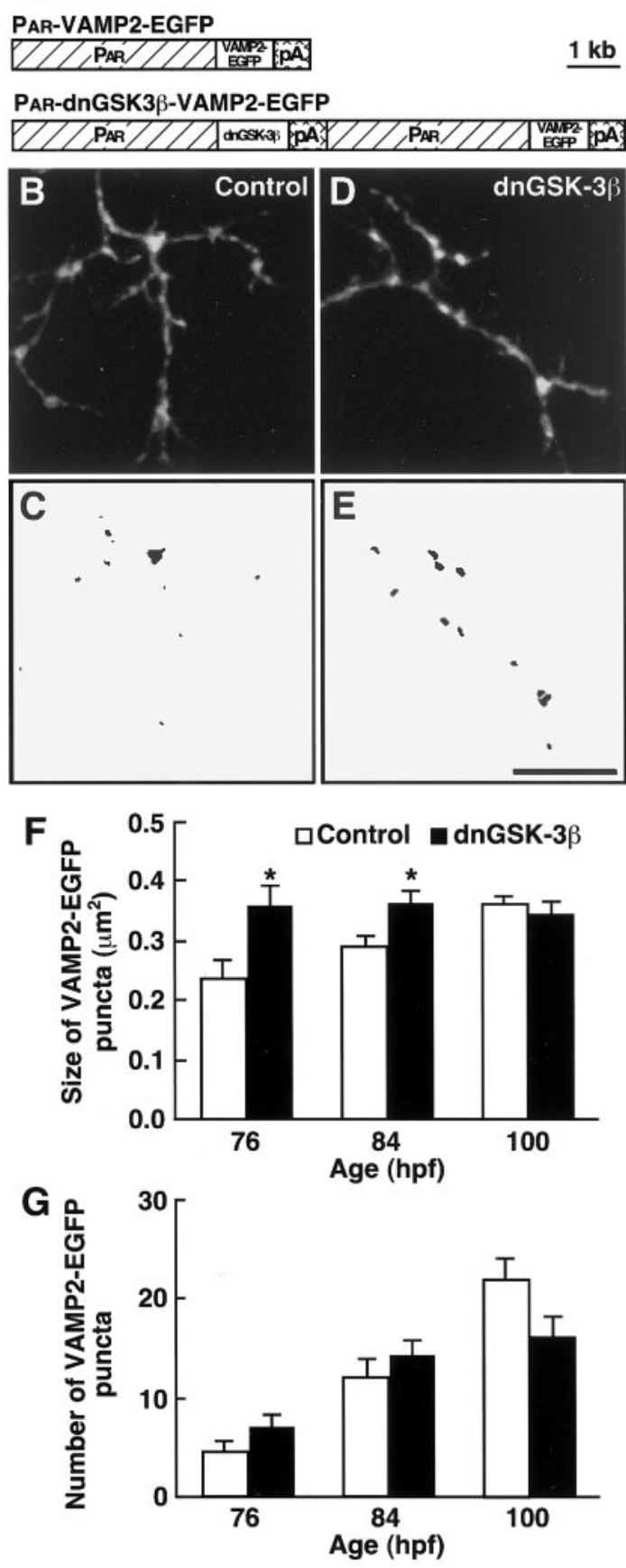

Figure 7. Effect of the dominant-negative form of GSK-3 $\beta$ on the development of VAMP2-EGFP puncta in RGC axon terminals. $A$, Vectors used for the expression of VAMP2-EGFP and dnGSK-3 $\beta$. $p A$, Polyadenylation signal $B, D$, Representative VAMP2-EGFP expression signals in the RGC axon terminals of PAR-VAMP2-EGFP-injected control $(B)$ and PAR-dnGSK-3 $\beta$-VAMP2-EGFP-injected $(D)$ embryos at 76 hpf. $C, E$, The threshold images of VAMP2-EGFP signals in $B$ and $D$ for evaluation of VAMP2-EGFP puncta. Scale bar, $10 \mu \mathrm{m}$. $F$, The size of VAMP2EGFP puncta in RGC axon terminals of PAR-VAMP2-EGFP-injected control ( $n=74,16$ embryos at $76 \mathrm{hpf} ; n=216,18$ embryos at $84 \mathrm{hpf} ; n=$ 508,23 embryos at $100 \mathrm{hpf}$ ) and PAR-dnGSK-3 $\beta$-VAMP2-EGFPinjected ( $n=85,12$ embryos at $76 \mathrm{hpf} ; n=354,25$ embryos at $84 \mathrm{hpf} ; n=$ 242,15 embryos at $100 \mathrm{hpf}$ ) embryos. * $p<0.05$; $t$ test. $G$, The number of VAMP2-EGFP puncta in RGC axon terminals of PAR-VAMP2-EGFPinjected control ( $n=16$ at $76 \mathrm{hpf} ; n=18$ at $84 \mathrm{hpf} ; n=23$ at $100 \mathrm{hpf})$ and PAR-dnGSK-3 $\beta$-VAMP2-EGFP-injected ( $n=12$ at $76 \mathrm{hpf} ; n=25$ at 84 hpf; $n=15$ at $100 \mathrm{hpf}$ ) embryos.
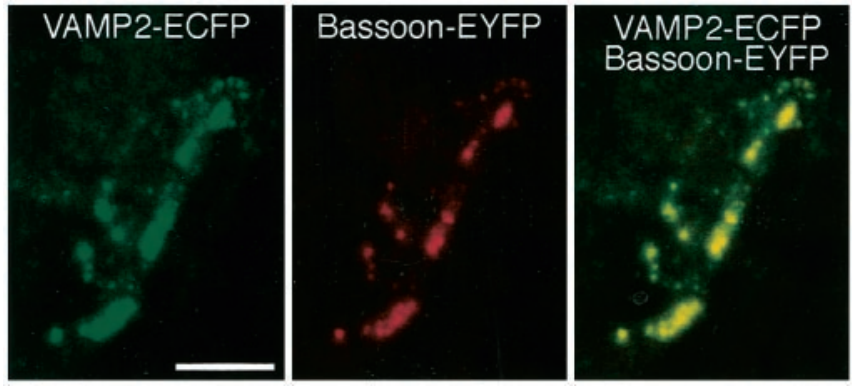

Figure 8. Colocalization of VAMP2-ECFP and Bassoon-EYFP in RGC axon terminals. Zebrafish embryos were coinjected with PARBassoon-EYFP and PAR-VAMP2-ECFP. VAMP2-ECFP and BassoonEYFP signals in a single RGC axon terminal at $96 \mathrm{hpf}$ were visualized with a HeCd laser (left) and an Ar laser (middle), respectively. These images are merged on the right. Scale bar, $10 \mu \mathrm{m}$.

fluorescent signals in RGCs first appeared at $\sim 30 \mathrm{hpf}$. This observation is consistent with the previous reports that zebrafish RGCs start to differentiate at this stage (Malicki, 1999; Schmitt and Dowling, 1999), and the expression of the chicken $n A C h R \beta 3$ gene starts just before the last $\mathrm{S}$ phase of the RGC precursor cells in the retina (Matter et al., 1995). The wide distribution of EGFP expression signals in the RGC layer of the transgenic lines conforms to the previous observation that goldfish $n A C h R \beta 3$ genes are expressed in most RGCs (Cauley et al., 1990). The time course of RGC axon projection to the tectum and expansion in the tectum followed by EGFP expression signals in the transgenic zebrafish lines is consistent with the previous studies by Stuermer (1988) and Burrill and Easter (1994) with horseradish peroxidase and DiI staining methods. In vivo observations of the entire RGC axon projections to the tectum in living zebrafish embryos elucidated that the development of RGC axon terminals in the tectum proceeded in two phases, the initial rapid expansion and arbor formation phase and the later slow arbor growth phase continuing thereafter. The development of RGC axon projections to the tectum was not uniform, because the meshwork of thick axon bundles developed prominently in the lateral tectum.

The elucidation of the molecular mechanisms determining the axonal projection field is an important issue to understand the neural circuit formation and brain functioning. Zebrafish GSK-3 $\beta$ is expressed in head regions, including the eye primordium, from early developmental stages (Tsai et al., 2000). Thus, GSK-3 $\beta$ should have been expressed from the initial axonogenesis stage of the RGC development. Consistently, GSK-3 $\beta$ is expressed in differentiated Xenopus RGCs from early developmental stages of the retinotectal projection (Marcus et al., 1998), and GSK-3 $\beta$ is localized at the growth cone in chick dorsal root ganglion cells (Eickholt et al., 2002). The $n A C h R \beta 3$ gene promoter-directed expression vector strategy enabled us to examine the role of GSK- $3 \beta$ specifically in the development of RGC axon projections to the tectum from $30 \mathrm{hpf}$. We found that the expression of a dominant-negative form of zebrafish GSK-3 $\beta$ suppressed the projection field of RGC axon terminals in the tectum, as shown by the reduction of arbor branch length and arbor areas. The effect cannot be ascribed to the delay of the axonal extension, because the number of RGCs extending to the tectum and the arbor length and arborization areas of RGC axon terminals at 76 hpf were comparable between the PAR-dnGSK$3 \beta$-EGFP-injected and control embryos. The suppressive effect of dnGSK-3 $\beta$ became apparent at later stages. We also found that 
dnGSK-3 $\beta$ significantly decreased the number of added branch tips in RGC axon terminals from 84 to $100 \mathrm{hpf}$, whereas the numbers of deleted branch tips were comparable between the control and dnGSK- $3 \beta$-injected embryos. These results suggest that GSK- $3 \beta$ activity is important for regulating the branching of RGC axon terminals and for determining their arborization field in the tectum.

VAMP2-EGFP is a well characterized marker of synaptic vesicles (Miesenbock et al., 1998; Nonet, 1999; Ahmari et al., 2000; Alsina et al., 2001). In the RGC axon terminals of control embryos injected with PAR-VAMP2-EGFP, most VAMP2EGFP puncta were localized in varicosities. In addition, punctate VAMP2-ECFP signals were merged well with those of BassoonEYFP signals, supporting their localization near the active zone of presynaptic nerve terminals (tom Dieck et al., 1998; Dresbach et al., 2001). From 76 to $100 \mathrm{hpf}$, the size and number of VAMP2EGFP puncta in the RGC axon terminals of control embryos increased, suggesting the presynaptic development during these stages. Consistently, the visual responses of zebrafish start from 68 to $79 \mathrm{hpf}$ (Easter and Nicola, 1996). We found that suppression of GSK-3 $\beta$ activity increased the size of VAMP2-EGFP puncta in RGC axon terminals at the initial stages of innervation to the tectum (76 and $84 \mathrm{hpf}$ ), whereas the numbers of puncta were similar to those in the controls. The size of the puncta in the RGC axon terminals of dnGSK- $3 \beta$-injected embryos was comparable with that in control embryos at the later stage of development (100 hpf). Thus, suppression of GSK-3 $\beta$ may stimulate the maturation of RGC axon terminals and accumulation of synaptic vesicles. Interestingly, in this respect, in vitro studies showed that lithium inhibited neurite extension of cultured hippocampal neurons (Takahashi et al., 1999) and induced synapsin I clustering in cerebellar granule cells and pontine neurons (Lucas and Salinas, 1997; Hall et al., 2000).

We showed that the expression of the dominant-negative GSK-3 $\beta$ mutant affected the final axonal arborization step, when RGC axons interacted with the dendrites of tectal neurons. The activity of GSK- $3 \beta$ is under complex regulation involving activating and inhibiting mechanisms, scaffold complexes, and differential recognition of target substrates (Kim and Kimmel, 2000; Grimes and Jope, 2001). Regulation by Wnt signaling (He et al., 1995) and by PI3K-PKB/Akt-mediated growth factor signaling (Cross et al., 1995) represents the canonical inhibitory pathway. Wnt or growth factors from target tectal neurons are good candidates of the regulators of GSK-3 $\beta$ activity in RGC axonal terminals because some of the zebrafish wnt-related genes are expressed in the tectum during embryogenesis (Molven et al., 1991; Krauss et al., 1992), and two insulin-like growth factor I receptors and their ligands are expressed widely in zebrafish embryos (Ayaso et al., 2002; Maures et al., 2002). Among diverse proteins phosphorylated by GSK-3 $\beta$, microtubule-associated protein $1 \mathrm{~B}$ (MAP1B) is implied in the axon terminal development. Mutation of the Drosophila MAP1B homolog gene futsch disturbed synaptic microtubule organization and increased the size of synaptic bouton (Hummel et al., 2000; Roos et al., 2000). Lithium, an inhibitor of GSK-3 $\beta$, induced microtubule reorganization of cultured dorsal root ganglion cells and cerebellar mossy fibers in vitro (Lucas et al., 1998; Hall et al., 2000). Thus, it is possible that GSK-3 $\beta$ may regulate the arborization and maturation of RGC axon terminals through phosphorylation of MAP1B.

Both the activity-independent and activity-dependent mechanisms underlie the arbor elaboration of retinotectal projection during development (Goodman and Shatz, 1993). Zou and Cline
(1999) showed that, in the developing Xenopus tadpole retinotectal projection, postsynaptic calcium/calmodulin-dependent protein kinase II was necessary to limit the growth of presynaptic and postsynaptic arbor structures in vivo. Tectal cell expression of the activity-regulated candidate plasticity gene 15 (cpg15) increased the elaboration of Xenopus retinal axons (Cantallops et al., 2000). Alsina et al. (2001) reported that brain-derived neurotrophic factor increased axon arborization and synapse number of Xenopus RGCs. Blockade of action potentials by application of tetrodotoxin to zebrafish larvae between 2 and $4 \mathrm{dpf}$ exerted little effect on the RGC arbor fields in the tectum (Stuermer et al., 1990), but treatment with the drug between 4 and $6 \mathrm{dpf}$ resulted in the enlargement of the projection field of RGC axons (Gnuegge et al., 2001). Treatment of zebrafish larvae with MK-801 [5-methyl-10,11dihydro-5H-dibenzo[a,d]cyclohepten-5,10-imine maleate], an inhibitor of the NMDA receptor, from 3 to $5 \mathrm{dpf}$ increased the retinotectal arbor size (Schmidt et al., 2000). Because dnGSK-3 $\beta$ exerted its effects on RGC axon arborization from 3 to $4 \mathrm{dpf}$, GSK- $3 \beta$ may play a role in the activity-independent mechanism. Although the upstream and downstream signaling of GSK-3 $\beta$ in zebrafish retinotectal projection and the activity dependence remain to be studied, our results provide evidence that GSK-3 $\beta$ regulates the arborization field and maturation of RGC axon terminals in vivo.

\section{REFERENCES}

Ahmari SE, Buchanan J, Smith SJ (2000) Assembly of presynaptic active zones from cytoplasmic transport packets. Nat Neurosci 3:445-451.

Alsina B, Vu T, Cohen-Cory S (2001) Visualizing synapse formation in arborizing optic axons in vivo: dynamics and modulation by BDNF. Nat Neurosci 4:1093-1101

Ayaso E, Nolan CM, Byrnes L (2002) Zebrafish insulin-like growth factor-I receptor: molecular cloning and developmental expression. Mol Cell Endocrinol 191:137-148.

Burrill JD, Easter Jr SS (1994) Development of the retinofugal projections in the embryonic and larval zebrafish (Brachydanio rerio). J Comp Neurol 346:583-600.

Cantallops I, Haas K, Cline HT (2000) Postsynaptic CPG15 promotes synaptic maturation and presynaptic axon arbor elaboration in vivo. Nat Neurosci 3:1004-1011.

Cauley K, Agranoff BW, Goldman D (1989) Identification of a novel nicotinic acetylcholine receptor structural subunit expressed in goldfish retina. J Cell Biol 108:637-645.

Cauley K, Agranoff BW, Goldman D (1990) Multiple nicotinic acetylcholine receptor genes are expressed in goldfish retina and tectum. J Neurosci 10:670-683.

Cline HT, Constantine-Paton M (1990) NMDA receptor agonist and antagonists alter retinal ganglion cell arbor structure in the developing frog retinotectal projection. J Neurosci 10:1197-1216.

Cross DAE, Alessi DR, Cohen P, Andjelkovich M, Hemmings BA (1995) Inhibition of glycogen synthase kinase-3 by insulin mediated by protein kinase B. Nature 378:785-789.

Deneris ES, Boulter J, Swanson LW, Patrick J, Heinemann S (1989) B3: a new member of nicotinic acetylcholine receptor gene family is expressed in brain. J Biol Chem 264:6268-6272.

Dominguez I, Green JBA (2001) Missing links in GSK3 regulation. Dev Biol 235:303-313.

Dresbach T, Hempelmann A, Spilker C, Zuschratter W, Garner CC, Gundelfinger ED (2001) Presynaptic targeting of the active zone cytomatrix protein bassoon in cultured hippocampal neurons. Soc Neurosci Abstr 27:278.6.

Easter Jr SS , Nicola GN (1996) The development of vision in the zebrafish (Danio rerio). Dev Biol 180:646-663.

Eickholt BJ, Walsh FS, Doherty P (2002) An inactive pool of GSK-3 at the leading edge of growth cone is implicated in semaphorin $3 \mathrm{~A}$ signaling. J Cell Biol 157:211-217.

Elliott KJ, Ellis SB, Berckhan KJ, Urrutia A, Chavez-Noriega LE, Johnson EC, Velicelebi G, Harpold MM (1996) Comparative structure of human neuronal $\alpha 2-\alpha 7$ and $\beta 2-\beta 4$ nicotinic acetylcholine receptor subunits and functional expression of the $\alpha 2, \alpha 3, \alpha 4, \alpha 7, \beta 2$, and $\beta 4$ subunits. J Mol Neurosci 7:217-228.

Gnuegge L, Schmid S, Neuhauss SC (2001) Analysis of the activitydeprived zebrafish mutant macho reveals an essential requirement of neuronal activity for the development of a fine-grained visuotopic map. J Neurosci 21:3542-3548. 
Goodman CS, Shatz CJ (1993) Developmental mechanisms that generate precise patterns of neuronal connectivity. Cell [Suppl] 72:77-98.

Grimes CA, Jope RS (2001) The multifaceted roles of glycogen synthase kinase $3 \beta$ in cellular signaling. Prog Neurobiol 65:391-426.

Hall AC, Lucas FR, Salinas PC (2000) Axonal remodeling and synaptic differentiation in the cerebellum is regulated by WNT-7a signaling. Cell 100:525-535.

He X, Saint-Jeannet JP, Woodgett JR, Varmus HE, Dawid IB (1995) Glycogen synthase kinase-3 and dorsoventral patterning in Xenopus embryos. Nature 374:617-622.

Hernandez MC, Erkman L, Matter-Sadzinski L, Roztocil T, Ballivet M, Matter JM (1995) Characterization of the nicotinic acetylcholine receptor $\beta 3$ gene. J Biol Chem 270:3224-3233.

Hoeflich KP, Luo J, Rubie EA, Tsao MS, Jin O, Woodgett JR (2000) Requirement for glycogen synthase kinase-3 $\beta$ in cell survival and NF-kappaB activation. Nature 406:86-90.

Hummel T, Krukkert K, Roos J, Davis G, Klambt C (2000) Drosophila Futsch/22C10 is a MAP1B-like protein required for dendritic and axonal development. Neuron 26:357-370.

Kim L, Kimmel AR (2000) GSK3, a master switch regulating cell-fate specification and tumorigenesis. Curr Opin Genet Dev 10:508-514.

Krauss S, Korzh V, Fjose A, Johansen T (1992) Expression of four zebrafish wnt-related genes during embryogenesis. Development 116:249-259.

Leroy K, Brion JP (1999) Developmental expression and localization of glycogen synthase kinase-3 $\beta$ in rat brain. J Chem Neuroanat 16:279-293.

Lucas FR, Salinas PC (1997) WNT-7a induces axonal remodeling and increases synapsin I levels in cerebellar neurons. Dev Biol 192:31-44.

Lucas FR, Goold RG, Gordon-Weeks PR, Salinas PC (1998) Inhibition of GSK- $3 \beta$ leading to the loss of phosphorylated MAP-1B is an early event in axonal remodelling induced by WNT-7a or lithium. J Cell Sci 111:1351-1361.

Lucas JJ, Hernandez F, Gomez-Ramos P, Moran MA, Hen R, Avila J (2001) Decreased nuclear $\beta$-catenin, tau hyperphosphorylation and neurodegeneration in GSK-3 $\beta$ conditional transgenic mice. EMBO J 20:27-39.

Malicki J (1999) Development of the retina. Methods Cell Biol 59:273-299.

Marcus EA, Kintner C, Harris W (1998) The role of GSK3 $\beta$ in regulating neuronal differentiation in Xenopus laevis. Mol Cell Neurosci 12:269-280.

Matter JM, Matter-Sadzinski L, Ballivet M (1995) Activity of the $\beta 3$ nicotinic receptor promoter is a marker of neuron fate determination during retina development. J Neurosci 15:5919-5928

Maures T, Chan SJ, Xu B, Sun H, Ding J, Duan C (2002) Structural, biochemical, and expression analysis of two distinct insulin-like growth factor I receptors and their ligands in zebrafish. Endocrinology 143:1858-1871.

Miesenbock G, De Angelis DA, Rothman JE (1998) Visualizing secretion and synaptic transmission with $\mathrm{pH}$-sensitive green fluorescent proteins. Nature 394:192-195.

Molven A, Njolstad PR, Fjose A (1991) Genomic structure and restricted neural expression of the zebrafish wnt-1 (int-1) gene. EMBO J 10:799-807.

Mori H, Miyazaki Y, Morita T, Nitta H, Mishina M (1994) Different spatio-temporal expressions of three otx homeoprotein transcripts during zebrafish embryogenesis. Brain Res Mol Brain Res 27:221-231.
Nonet ML (1999) Visualization of synaptic specializations in live $C$. elegans with synaptic vesicle protein-GFP fusions. J Neurosci Methods 89:33-40.

Roos J, Hummel T, Ng N, Klambt C, Davis GW (2000) Drosophila Futsch regulates synaptic microtubule organization and is necessary for synaptic growth. Neuron 26:371-382.

Schmidt JT, Buzzard M, Borress R, Dhillon S (2000) MK801 increases retinotectal arbor size in developing zebrafish without affecting kinetics of branch elimination and addition. J Neurobiol 42:303-314.

Schmitt EA, Dowling JE (1999) Early retinal development in the zebrafish, Danio rerio: light and electron microscopic analyses. J Comp Neurol 404:515-536.

Shepherd GMG, Harris KM (1998) Three-dimensional structure and composition of CA3 $\rightarrow$ CA1 axons in rat hippocampal slices: implications for presynaptic connectivity and compartmentalization. J Neurosci 18:8300-8310.

Silver MA, Stryker MP (2000) A method for measuring colocalization of presynaptic markers with anatomically labeled axons using double label immunofluorescence and confocal microscopy. J Neurosci Methods 94:205-215.

Stern EA, Maravall M, Svoboda K (2001) Rapid development and plasticity of layer 2/3 maps in rat barrel cortex in vivo. Neuron 31:305-315.

Stuermer CAO (1988) Retinotopic organization of the developing retinotectal projection in the zebrafish embryo. J Neurosci 8:4513-4530.

Stuermer CAO, Rohrer B, Munz H (1990) Development of the retinotectal projection in zebrafish embryos under TTX-induced neuralimpulse blockade. J Neurosci 10:3615-3626.

Takahashi M, Tomizawa K, Kato R, Sato K, Uchida T, Fujita SC, Imahori K (1994) Localization and developmental changes of tau protein kinase I/glycogen synthase kinase- $3 \beta$ in rat brain. J Neurochem 63:245-255.

Takahashi M, Yasutake K, Tomizawa K (1999) Lithium inhibits neurite growth and tau protein kinase I/glycogen synthase kinase-3 $\beta$ dependent phosphorylation of juvenile tau in cultured hippocampal neurons. J Neurochem 73:2073-2083.

tom Dieck S, Sanmarti-Vila L, Langnaese K, Richter K, Kindler S, Soyke A, Wex H, Smalla KH, Kampf U, Franzer JT, Stumm M, Garner CC, Gundelfinger ED (1998) Bassoon, a novel zinc-finger CAG/glutaminerepeat protein selectively localized at the active zone of presynaptic nerve terminals. J Cell Biol 142:499-509.

Tsai JN, Lee CH, Jeng H, Chi WK, Chang WC (2000) Differential expression of glycogen synthase kinase 3 genes during zebrafish embryogenesis. Mech Dev 91:387-391.

Westerfield M (1995) The zebrafish book. Eugene, OR: University of Oregon.

Woodgett JR (1990) Molecular cloning and expression of glycogen synthase kinase-3/factor A. EMBO J 9:2431-2438.

Yoshida T, Ito A, Matsuda N, Mishina M (2002) Regulation by protein kinase A switching of axonal pathfinding of zebrafish olfactory sensory neurons through the olfactory placode-olfactory bulb boundary. J Neurosci 22:4964-4972.

Zou DJ, Cline HT (1996) Expression of constitutively active CaMKII in target tissue modifies presynaptic axon arbor growth. Neuron 16:529-539.

Zou DJ, Cline HT (1999) Postsynaptic calcium/calmodulin-dependent protein kinase II is required to limit elaboration of presynaptic and postsynaptic neuronal arbors. J Neurosci 19:8909-8918. 